\title{
D-Amphetamine Boosts Language Learning Independent of its Cardiovascular and Motor Arousing Effects
}

\author{
Caterina Breitenstein*,', Stefanie Wailke', Stefan Bushuven', Sandra Kamping', Pienie Zwitserlood², \\ E Bernd Ringelstein' and Stefan Knecht' \\ 'Department of Neurology, University of Münster, Germany; ${ }^{2}$ Department of Psychology, University of Münster, Germany
}

\begin{abstract}
D-Amphetamine (AMPH) was effective in a number of studies on motor and language recovery after stroke, but given safety concerns, its general use after stroke is still debated. Most stroke patients are excluded from treatment because of a significant risk of cardiovascular dysregulation. AMPH acts on multiple transmitter systems, and mainly the noradrenergic actions are related to the cardiovascular effects. If AMPH's cardiovascular and arousal effects were correlated with its plasticity-enhancing effects in humans, this would imply that desired and undesired effects are inevitably tied. If not, improved cerebral reorganization may not be mediated by AMPH's arousing effects and could be achieved with substances lacking the undesired cardiovascular effects. As a model for language recovery after stroke, we used a prospective, randomized, double-blind, placebo-controlled design and taught 40 healthy male subjects an artificial vocabulary of 50 concrete nouns over the course of five consecutive training days (high-frequency training). The associative learning principle involved higher co-occurrences of 'correct' picturepseudoword pairings as compared to 'incorrect' pairings. Subjects received either AMPH $(0.25 \mathrm{mg} / \mathrm{kg})$ or placebo 90 min prior to training on each day. Novel word learning was significantly faster and better in the AMPH as compared to the placebo group. Increased learning success was maintained I month post-training. No correlation was found between training success and drug-induced increases in blood pressure, heart rate, or a facilitation of simple motor reaction time. Our data show that AMPH's plasticity-enhancing effect in humans is not related to its cardiovascular arousal. This suggests that the beneficial effects in stroke patients could also be obtained by less cardiovascular active drugs. Neuropsychopharmacology (2004) 29, 1704-17|4, advance online publication, 28 April 2004; doi: 10. I038/s.npp. 1300464
\end{abstract}

Keywords: stroke; D-amphetamine; aphasia; neuronal plasticity; memory consolidation

\section{INTRODUCTION}

Over the past decade, there has been an increasing interest in drugs enhancing brain plasticity after stroke. Animal work and clinical trials with stroke patients indicate that pharmacological interventions coupled with intensive behavioral training can enhance recovery after stroke (for a summary, see Gladstone and Black, 2000).

When coadministered with behavioral training and in sufficient doses, ${ }^{1}$ the most promising drug in both motor (Crisostomo et al, 1988; Walker-Batson et al, 1995) and language (Walker-Batson et al, 1992; Walker-Batson, 2000;

\footnotetext{
*Correspondence: Dr C Breitenstein, Department of Neurology, University of Münster, Albert-Schweitzer-Strasse 33, 48I29 Münster, Germany, Tel: + 49 25I 8349969, Fax: + 49 25। 8348।81, E-mail: caterina.breitenstein@uni-muenster.de

Received 10 December 2003; revised 24 February 2004; accepted I8 March 2004

Online publication: 22 March 2004 at http://www.acnp.org/citations/ Npp03220403558

${ }^{1}$ A recent study (Sonde et al, 2001) did not find superior motor recovery in the D-amphetamine (AMPH) as compared to the placebo group. However, two weekly doses of $10 \mathrm{mg}$ AMPH may not have been sufficient. Besides, the AMPH group was significantly older than the placebo group. Similar criticism applies to a recent study by Treig et al (2003).
}

Walker-Batson et al, 2001) recovery after stroke has so far been AMPH (for a recent review, see Martinsson and Eksborg, 2004). Details of the mechanism are not fully understood. Based on animal studies, however, it is assumed that AMPH increases general brain excitability through its noradrenergic actions (Boyeson and Feeney, 1990; Feeney et al, 1982; Feeney and Hovda, 1985; Hovda and Feeney, 1984) and thus supports the formation of new neural networks under conditions of intense sensory stimulation (Goldstein, 1999; Groves and Rebec, 1976). Therefore, cardiovascular dysregulation like elevated systolic blood pressure and heart rate, resulting from the increased noradrenergic drive, is often considered the flip side of the plasticity-enhancing effect of amphetamine (Goldstein, 1997; Martinsson and Wahlgren, 2003). These critical cardiovascular side effects and a trend towards increased mortality ${ }^{2}$ in stroke patients (Martinsson et al, 2003) leave only a fraction of stroke patients eligible for

\footnotetext{
${ }^{2}$ The authors of the Cochrane review recently clarified that (a) the increased mortality in AMPH-treated stroke patients may be confounded by baseline differences between groups (more severe cases were allocated to the AMPH group), (b) AMPH was administered in the very acute stages after stroke in the two studies observing higher mortality rates, and (c) death occurred after discontinuation of AMPH (cf Martinsson and Eksborg, 2004).
} 
treatment with AMPH. In a recent study by Walker-Batson et al (2001), a mere $2.5 \%$ of available stroke patients qualified for treatment. Among the most frequent exclusion reasons was evidence of hemorrhagic stroke, because a sudden increase in blood pressure following AMPH presents a major risk factor for a stroke relapse. No study with humans to date has examined, however, whether cardiovascular side effects and plasticity-enhancing effects of AMPH are correlated, that is, whether the increase in blood pressure is directly related to the extent of successful learning.

$\mathrm{AMPH}$ modulates a variety of neurotransmitter systems of the brain other than noradrenaline, particularly dopamine (Cardenas et al, 2004; Groves and Rebec, 1976). Dopamine seems to be effective not only in enhancing working memory in healthy subjects (Barch, 2004) and ameliorating cognitive deficits in the early stages of Parkinson's disease (eg Kulisevsky, 2000) but also in motor recovery after stroke in humans (Scheidtmann et al, 2001) and in boosting of language learning in healthy subjects (Knecht et al, 2004). Even though a small fraction $(<5 \%)$ of levodopa is hydroxylated to norepinephrine (Nutt and Fellman, 1984), the cardiovascular and plasticity effects of AMPH could thus be dissociated on a molecular level, with the dopamine effects being relevant for brain plasticity. If plasticity enhancement could be achieved without putting the patient at risk for cardiovascular side effects, the percentage of eligible stroke patients would increase dramatically.

Our aims were to investigate the plasticity-enhancing effects of AMPH on language acquisition in healthy adults and to examine the correlations between arousal effects, as assessed by cardiovascular and motor activations, on the other hand, and brain plasticity effects on the other. The association between putative dopaminergic effects, as assessed by motivation measures, and improvement of learning was also analyzed. Furthermore, we focused on language plasticity because major therapeutic advances in the treatment of aphasia are lacking and because of preliminary evidence that AMPH is a promising pharmacological adjunct to language therapy (Walker-Batson et al, 2001). Even though we ran healthy subjects, our design serves as a model of language reacquisition after stroke. Associative learning presents one of the major principles underlying acquisition of a novel vocabulary in children and adults (cf Breitenstein and Knecht, 2003), and we therefore developed a word-learning training program that was based on the principles of statistical learning. The study outcome will have obvious implications for functional recovery in aphasia after stroke, but will additionally open new perspectives for the development of future pharmacological options to enhance plasticity in stroke patients with deficits other than language.

\section{MATERIALS AND METHODS}

\section{Subjects}

A total of 40 healthy male subjects (20-33 years) participated in this prospective, randomized, double-blind, placebocontrolled trial with 20 valid cases in each group. Owing to the potentially hazardous effects of AMPH during pregnancy, only male subjects were included. The AMPHETAMINE group was treated with $0.25 \mathrm{mg} / \mathrm{kg}$ bodyweight of
AMPH. The PLACEBO group received a standard placebo substance (99.5\% Mannitol, 0.5\% Erosil) in identical capsules. Substances were administered $90 \mathrm{~min}$ prior to the language training on each of the five consecutive training days to achieve maximal blood plasma levels.

All subjects had completed the equivalent of a high school degree and were students recruited from the University of Münster, Germany. All participants were native German speakers and were raised in Germany. Subjects were righthanded, as assessed by the Edinburgh Handedness Inventory (Oldfield, 1971), and all were left-hemisphere dominant for language (Knecht et al, 1999).

Exclusion criteria included bilingualism, a history of neurological, psychiatric, or cardiological diagnoses, chronic or acute diseases, intake of drugs affecting the central nervous system up to 2 weeks prior to study participation, consumption of recreational drugs as assessed by a urinary drug screening test, a urine $\mathrm{pH}$-value $>6.5$, smoking of $>15$ cigarettes/day, or drinking $>6$ cups of coffee/day or of $>50 \mathrm{~g}$ of alcohol/day, or known drug allergies. To control for acute effects of caffeine and nicotine, subjects were instructed to refrain from caffeine and cigarette consumption at least $2 \mathrm{~h}$ prior to training on every training day.

Subjects' written informed consent was obtained according to the declaration of Helsinki. The Ethical Committee of the University of Münster had approved the study.

A comprehensive battery of neuropsychological tests was administered to all subjects in a separate session prior to language training, comprising tests of general intellectual functioning, attention, verbal fluency, digit spans, verbal and visuospatial memory, and personality scales.

\section{Protocol}

We recently developed a high-frequency, intensive, associative word-learning model to study the neural mechanisms of language learning and language-related brain plasticity. Details of our training program are described elsewhere (Breitenstein and Knecht, 2002). Briefly, from a set of 183 spoken pseudowords, 50 pseudowords were selected, which yielded few associations with existing words and were of neutral emotional valence. The selected pseudowords were paired with object drawings in a pseudorandomized manner, and each subject received a different combination of pairings. These auditory-visual pairs were used to train subjects solely on the basis of different frequencies of 'correct' and 'incorrect' pairings. The underlying learning principle is the higher statistical co-occurrence of certain couplings as compared to other pairings. The nature of our task should most appropriately be classified as an 'incidental associative learning' task. We chose incidental learning conditions to keep cognitive strategies relatively homogenous.

Subjects were trained every day for a duration of five consecutive days (see Figure 1). On each of the training days, they were presented with 400 trials of picturepseudoword couplings (separated by a break of $5 \mathrm{~min}$ after 200 trials). The training lasted for 30 min each day. Subjects' task was to decide on each trial whether the combination of pseudoword and picture was correct or incorrect. Learning reflects itself in increasing number of correct responses, deviating from the initial $50 \%$ chance level. On day 5 , after 


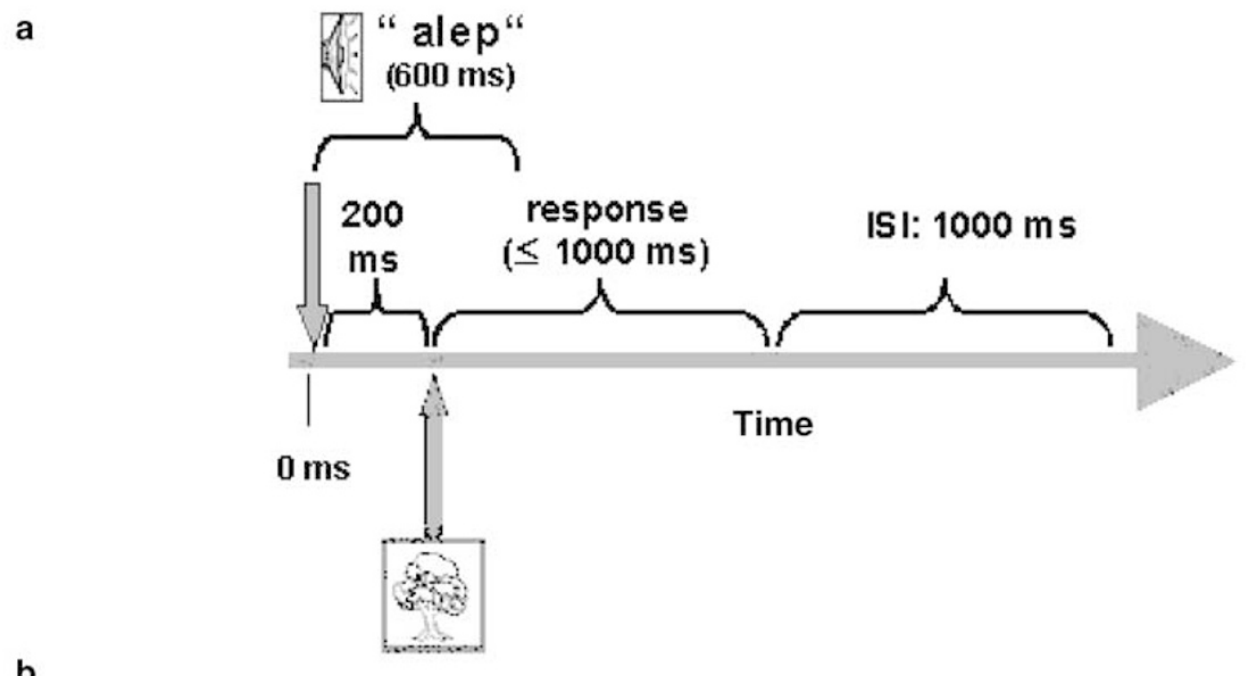

b

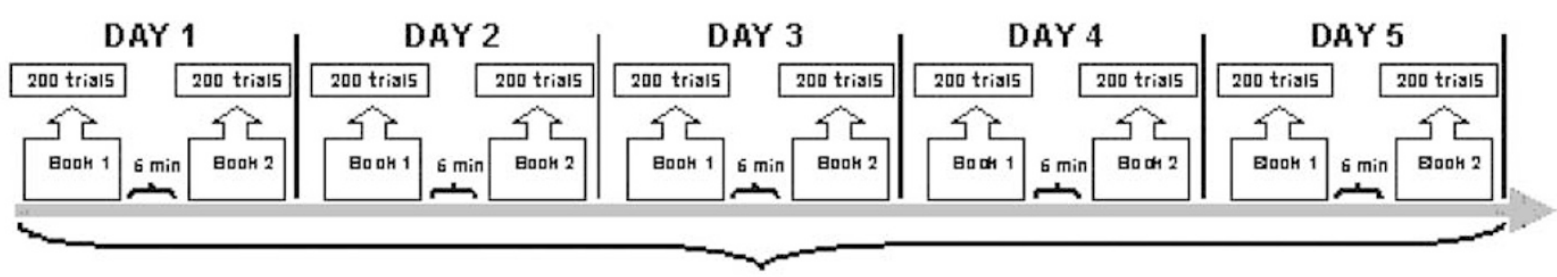

Training

Figure I Study design; (a) Example of a single trial. A picture of a common object is presented $200 \mathrm{~ms}$ after the onset of a spoken pseudoword. Subjects have to decide by button press within a I s window if object and pseudoword are correctly coupled; (b) Training sequence, ISI=interstimulus interval.

the regular training session, subjects' ability to correctly translate the pseudowords into their native language was assessed. The latter task comprised two blocks of 200 trials each, in which the German names of the objects were acoustically presented in pairs with pseudowords (eg the word 'Kerze' [candle] was acoustically presented together with the pseudoword 'binu'). Subjects had to indicate by button press, if the German word was the correct translation of the respective pseudoword. This transfer task assessed if subjects had explicit access to the pseudoword meanings. Retention assessed 1 week and 1 month after the last training day. The retention sessions were included to assess if memory consolidation under the influence of AMPH has measurable effects on the stability of these memories weeks to months later, long after active metabolites have been cleared.

Dependent variables were expressed as percentage of correct responses and reaction times.

To assess general motor arousal effects of AMPH, subjects were tested on a simple motor reaction time task with 100 trials prior to the language training on every day. The task consisted of pressing a button as quickly as possible after a tone was presented $(65 \mathrm{~dB}, 1000 \mathrm{~Hz})$. To assess cardiovascular arousal, blood pressure and heart rate were measured digitally every $30 \mathrm{~min}$ (bose medicus memory; Bosch, Germany), starting with the subject's arrival on a given training day.

Furthermore, to assess effects on motivation as a correlate of dopaminergic AMPH effects, subjects rated their subjective positive and negative feelings, using the Positive and Negative Affective Schedule every $30 \mathrm{~min}$ on a given training day (PANAS: Watson et al, 1988; German version: Krohne et al, 1996). The PANAS consists of two 10-item mood scales, which measure the dimensions Positive Affect (high score: a state of high energy; low score: sadness and lethargy) and Negative Affect (high score: state of distress; low score: state of calmness).

\section{Data Analysis}

Group differences on neuropsychological measures were analyzed using Bonferroni-corrected unpaired $t$-tests. Training data were analyzed using ANOVAs with a trend analysis on the repeated factors 'day' and 'block' and the between-subject factor 'group' (AMPHETAMINE, PLACEBO). For clarity of presentation, only significant effects involving the factor 'group' are reported. Post hoc group differences were analyzed using paired or unpaired $t$-tests, as appropriate. Correlations were examined using Bonferronicorrected Pearson correlation coefficients. The relationship between training success and measures of arousal or mood was additionally explored using a stepwise multiple regression analysis (forward entry; entry criterion: $p<0.05$ ).

\section{RESULTS}

There were no baseline group differences with respect to age, body weight (range: $65-90 \mathrm{~kg}$ ), daily consumption of nicotine and caffeine, number of languages spoken fluently, neuropsychological ( $\mathrm{cf}$ Table 1) or personality scale test scores. There were no serious adverse reactions to the drug. 
Table I Group Means and Standard Deviations of the Neuropsychological Background Measures and Correlation Coefficients (Pearson) with Training Success on the Artificial Language

\begin{tabular}{|c|c|c|c|c|}
\hline Test & Group & Mean & SD & $\begin{array}{c}\text { Correlation with training } \\
\text { success }(r)\end{array}$ \\
\hline Lateralization index for language (fTCD) & A & 4.4 & 2.1 & -0.18 \\
\hline \multirow[t]{2}{*}{ Edinburgh Handedness Inventory (laterality index) } & A & 93.5 & 9.9 & 0.14 \\
\hline & $P$ & 91.0 & 7.9 & -0.03 \\
\hline \multirow[t]{2}{*}{ Number of languages spoken fluently } & A & $2.5($ median $=2)$ & 1.5 & -0.07 \\
\hline & $P$ & $2.6($ median $=2)$ & I.1 & 0.26 \\
\hline \multirow[t]{2}{*}{ VLMT: list A leaning success (block 5 minus I) } & A & 4.6 & 2.4 & 0.35 \\
\hline & $P$ & 5.8 & 1.7 & 0.16 \\
\hline \multirow{2}{*}{ VLMT: interference list B } & A & 13.1 & 2.5 & 0.13 \\
\hline & $P$ & 12.6 & 2.4 & 0.50 \\
\hline \multirow[t]{2}{*}{ VLMT: delayed free recall } & A & 13.0 & 2.3 & -0.09 \\
\hline & $P$ & 12.4 & 2.7 & 0.49 \\
\hline \multirow[t]{2}{*}{ WMS paired associates: sum of blocks $1-3$} & A & 22.5 & 1.5 & 0.03 \\
\hline & $P$ & 20.7 & 3.5 & 0.38 \\
\hline WMS logical memory, delayed recall & $P$ & 11.7 & 4.3 & 0.34 \\
\hline \multirow[t]{2}{*}{ Rey-Figure, copy } & A & 34.5 & 1.7 & 0.29 \\
\hline & $P$ & 34.6 & 1.5 & 0.14 \\
\hline \multirow[t]{2}{*}{ Rey-Figure, delayed recall } & A & 29.4 & 4.5 & -0.07 \\
\hline & $P$ & 25.7 & 5.4 & 0.52 \\
\hline \multirow[t]{2}{*}{ RWT: word fluency (mean PR) } & A & 63.0 & 19.0 & 0.30 \\
\hline & $P$ & 63.4 & 20.3 & 0.35 \\
\hline \multirow[t]{2}{*}{ d2-Attention-test (PR) } & A & 81.7 & 18.3 & -0.07 \\
\hline & $P$ & 93.5 & 9.9 & 0.08 \\
\hline \multirow[t]{2}{*}{ WAIS-R: general knowlegde (WP) } & A & 13.6 & 2.2 & -0.15 \\
\hline & $P$ & 13.4 & 2.6 & 0.05 \\
\hline \multirow[t]{2}{*}{ WAIS-R: vocabulary (WP) } & $A$ & 14.3 & 1.7 & -0.04 \\
\hline & $P$ & 13.6 & 2.3 & 0.20 \\
\hline
\end{tabular}


Table I (Continued)

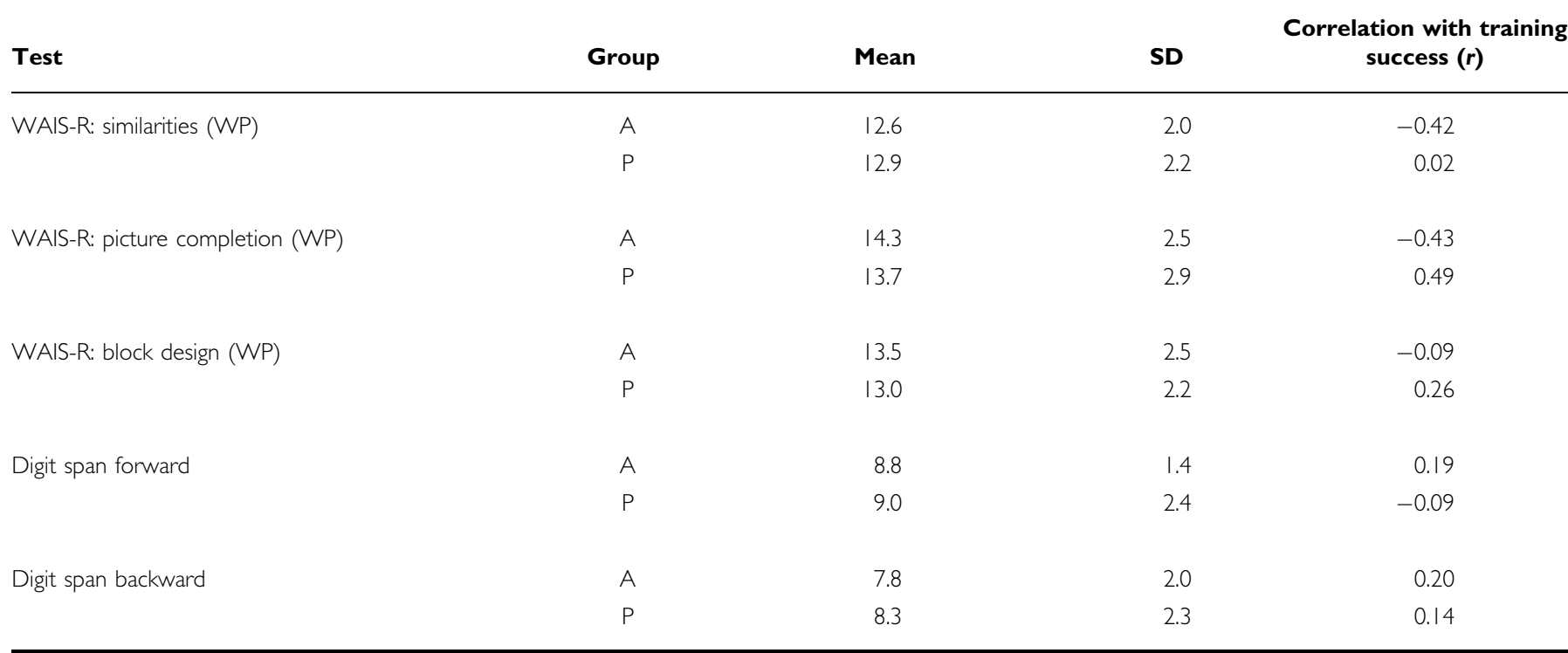

$\mathrm{SD}=$ standard deviation; $\mathrm{A}=\mathrm{AMPHETAMINE} ; \mathrm{P}=\mathrm{PLACEBO} ; \mathrm{fTCD}=$ functional transcranial Dopplersonography; VLMT = Verbaler Lern- und Merkfähigkeitstest (German version of the California Verbal Learning Test); RWT = Regensburger Wortflüssigkeitstest (German version of the Controlled Oral Word Association Test); WMS = Wechsler Memory Scale (German version); WAIS = Wechsler Adult Intelligence Scale (German version); PR = percent rank; WP =Wechsler points.

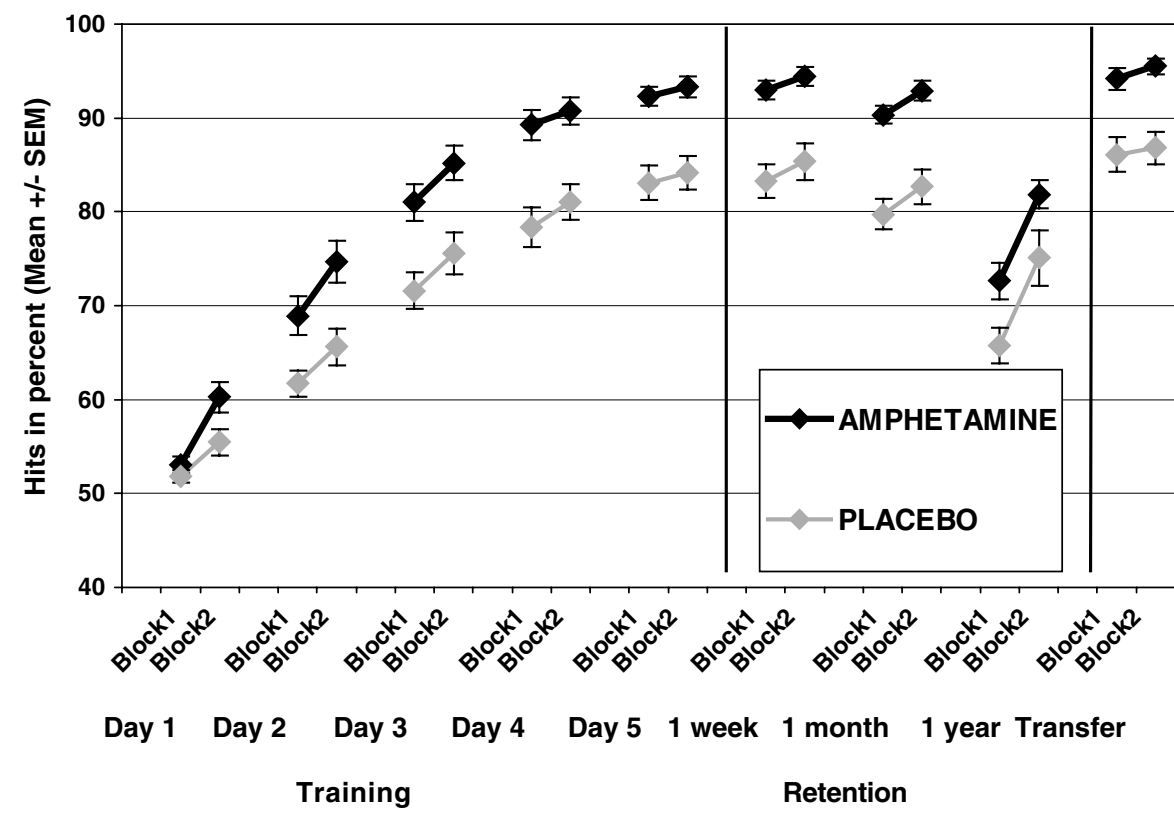

Figure 2 Learning curves across the five training days and the 1 -week, I-month, and $\mid-$-year $(n=2 \mid$ ) retention sessions for the two groups (AMPHETAMINE, PLACEBO). Scores on the transfer blocks, assessed immediately post-training on day 5, are also displayed.

\section{Language Training}

Learning speed was significantly accelerated in the AMPHETAMINE group compared to the PLACEBO group (group $\times$ day: linear trend, $F(1,38)=8.21, p<0.001$; cf Figure 2). Group differences were already noted on day 1 (block 2), and the group difference grew increasingly larger the following training days (all $t_{(38)}>2.17$, all $p<0.04$ ). The AMPHETAMINE group also significantly outperformed the
PLACEBO group at the two retention sessions 1 week and 1 month post-training (main effect of group, $F(1,38)=24.83$, $p<0.001) .12$ subjects in the AMPHETAMINE and nine subjects in the PLACEBO group could also be recruited for a third retention session after more than 1 year. Performance in both groups had deteriorated, but was still better than would have been expected by chance. Most importantly, group differences remained significant (main effect of group: $F(1,19)=6.21, p=0.02$; see Figure 2 ). 
As shown in Figure 2, both groups showed successful transfer from visual to spoken material. Again, performance in the AMPHETAMINE group was superior to the PLACEBO group (main effect of group: $F(1,38)=17.16$, $p<0.001)$.

There were no significant correlations between training success (day 5 minus day 1) and neuropsychological background measures or daily caffeine consumption for either group (see Table 1). With respect to habitual smoking status, however, we did observe a correlation between training success and number of cigarettes smoked daily in the AMPHETAMINE group (but not in the Placebo group). The correlation was negative (Spearman rank correlation coefficient: $r=-0.53, p=0.02)$, indicating that heavy smokers were poorer learners in the AMPHETAMINE group. This implies that group differences in language learning success may have been even more pronounced, if we had only included nonsmokers.

Response times during the language task decreased significantly across training days, but there were no significant effects involving the factor 'group'. The above reported group difference in steepness of the learning curves could therefore not be explained by group differences in accuracyspeed tradeoff.

\section{General Drug Arousal: Response Styles}

To determine whether the accelerated learning speed of the AMPHETAMINE group could be explained with a more risky, response style as part of the general drug arousal effect (eg more 'yes' responses' leading to more errors of the 'false alarm' type), subjects' responses were classified into hits, correct rejections, false alarms, and misses. An ANOVA with the factors response type (4) by day $(5) \times$ group yielded a significant three-way interaction (linear trend, $F(1,38)=5.73, p=0.02)$. Post hoc analyses showed that the linear increase of hits and the decrease of misses across days was steeper for the AMPHETAMINE compared to the PLACEBO group (linear trend, both $F(1,38)>4.00, p<0.05$; see Figure 3 ). Furthermore, the groups significantly differed on percent of hits and misses on days $2-5$ (all $p<0.02$ ). The result of a selective improvement in detection of 'correct' couplings demonstrates that AMPH specifically heightened subjects' sensitivity to the frequency principle of the task.

\section{Motor Arousal}

Simple motor reaction times. The response times for the AMPHETAMINE group decreased linearly from day 1 to day 5, whereas no change was observed in the PLACEBO

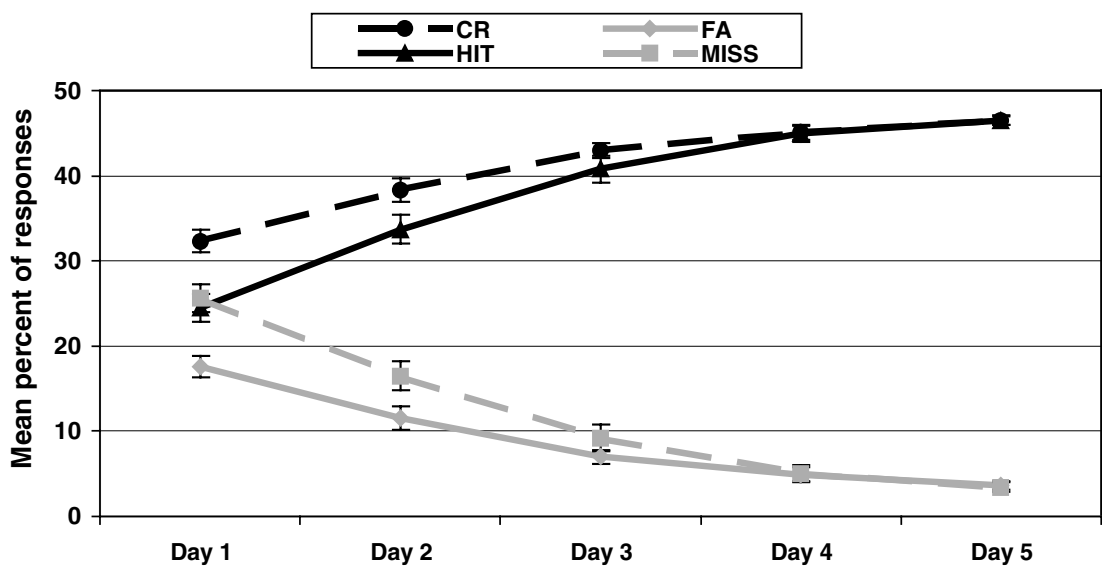

b

Response types in the PLACEBO group

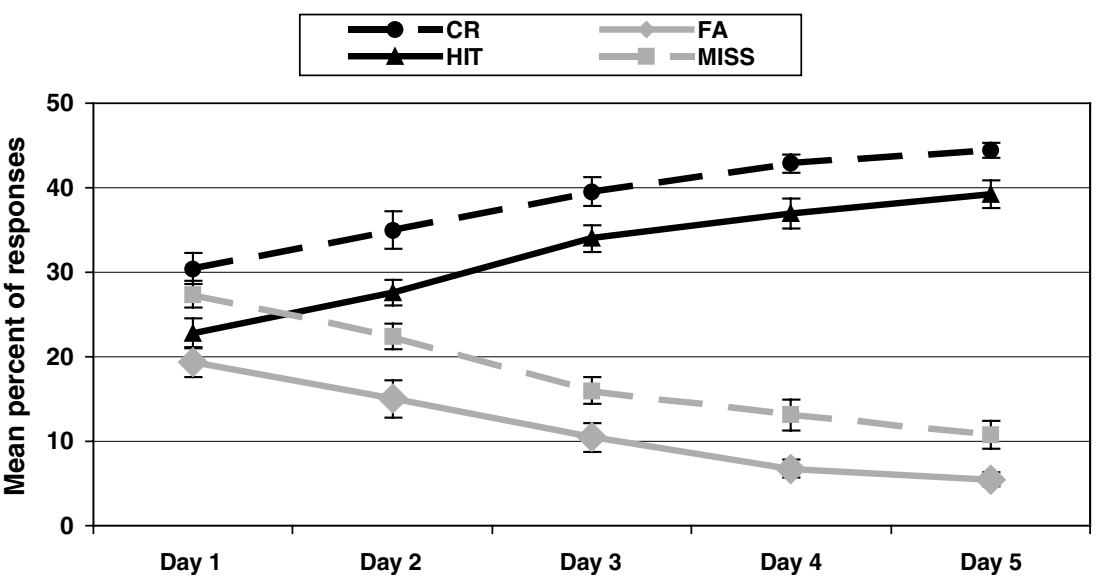

Figure 3 Means $(+/-S E M)$ for the four response types $(C R=$ correct rejections, $F A=$ false alarms; Hit $=$ hits; Miss $=$ misses $)$ across the five training days for the AMPHETAMINE group (top) and the PLACEBO group (bottom). 
group (day $\times$ group: linear trend, $F(1,38)=5.55, p=0.02$ ). Group differences were noted on days 4 and 5 and persisted at both the 1-week and 1-month retention sessions (all $\left.t_{(38)}>|2,11|, p<0.05\right)$. Correlations between the decrease in simple motor reaction time (day 1 minus day 5) and the improvement on the language training (day 5 minus day 1) were not significant for either group $(r<0.21)$.

\section{Cardiovascular Arousal}

Systolic and diastolic blood pressures. Initial systolic and diastolic blood pressures, assessed approximately 1 week prior to language training, were not different for the two groups (systole: means of 124 and 125, respectively; diastole: means of 74 and 75, respectively).

For diastolic blood pressure, no group differences emerged during training days. For the AMPHETAMINE group, systolic blood pressure increased over the $120 \mathrm{~min}$ of all sessions, whereas no change was seen in the PLACEBO group (sample $\times$ group: linear trend, $F(1,38)=$ $8.77, p<0.001)$. Group differences were significant at 30 , 60 , 90, and $120 \mathrm{~min}$ post-drug ingestion (all $t_{(38)}>2.13$, $p<0.05)$. There were, however, no significant correlations between systolic blood pressure increase over the $120 \mathrm{~min}$ of training and language learning success (day 5 minus day 1) for either group $(r<|0.21|)$.

Heart rat. The AMPHETAMINE group showed an increase in heart rate over the 120 min after drug ingestion, while the PLACEBO group demonstrated a significant decrease (sample $\times$ group: linear trend, $F(1,38)=10.79, p<0.001$ ). Groups differed at the $120 \mathrm{~min}$ sample only $\left(t_{(38)}=3.09\right.$, $p<0.01)$. There were no significant correlations between heart rate changes across the 120 min of training and language learning success (day 5 minus day 1) for either group $(r<|0.05|)$.

\section{Mood Measures}

Positive feelings. There were no baseline group differences in positive feelings on the first sample of day 1 prior to first substance ingestion. Groups differed significantly in their positive ratings across the samples taken within each session (sample $\times$ group, linear trend, $F(1,38)=14.71$, $p<0.001)$. Follow-up analyses showed that positive feelings increased over the 120 min of given training session in the AMPHETAMINE group (linear trend, $F(1,19)=12.54$, $p<0.001)$, whereas there was no significant change in the PLACEBO group (trend towards a decrease of positive feelings, $p=0.09$ ). The change in positive ratings (last sample minus first sample) correlated significantly with the learning success (day 5 minus day 1) in the AMPHETAMINE group only $(r=0.59, p=0.006)$. Furthermore, when repeating the above reported ANOVA of day by block by group for the learning rates and using the change in positive ratings as covariate, the group difference in learning rate was no longer significant. This elegantly demonstrated the effect of enhanced motivation on learning success.

Negative feelings. There were no baseline differences between groups on day 1 . Groups differed in ratings of negative feelings across training days (day $\times$ group: quad- ratic trend, $F(1,38)=6.17, p=0.01)$. The AMPHETAMINE group showed a decrease in negative feelings from day 1 to day 4 (quadratic trend, $F(1,19)=10.37, p<0.001$ ), whereas there was no systematic change in the PLACEBO group. Changes in negative feelings were not related to learning success on the language task for either group $(r<0.28)$.

\section{Best Predictor of Learning Success}

To examine which of the arousal or mood measures was the single best predictor of improvement in the artificial language acquisition program, a multiple regression analysis was conducted separately for each group. Training improvement from day 1 to 5 was used as the dependent variable, and the arousal measures (changes in simple motor time, systolic blood pressure, heart rate) and mood scores (changes in PANAS positive and negative ratings) scores served as predictor variables (see Figure 4 for correlations between arousal or mood measures and training success). This analysis revealed that training improvement was selectively predicted by an increase in positive mood rating, operating exclusively in the AMPHETAMINE group and explaining $35 \%$ of the variance in language learning $\left(R^{2}=0.35, \beta=0.59, F=9.71, p=0.006\right)$. The remaining predictor variables did not significantly contribute to the residual variance.

\section{DISCUSSION}

Our results demonstrate the efficacy of AMPH to enhance language plasticity in humans. AMPH not only accelerated learning across the five training days but also led to a superior retention of the acquired new vocabulary over the 1 -month retest period. Only five of the 40 subjects became aware of the underlying frequency principle, indicating that the associations were picked up intuitively by the majority of the subjects. The transfer test demonstrates, however, that subjects had explicit access to the correct translations of the pseudoword into their native language. Overall, our results corroborate (a) previous results on positive effects of AMPH in healthy subjects on verbal memory (Soetens et al, 1993; Soetens et al, 1995), attention and working memory performance (Mattay et al, 2000; Servan-Schreiber et al, 1998), reasoning (Mattay et al, 1996), response times during the Wisconsin Card Sorting Test (Mattay et al, 2003), and procedural learning (Kumari et al, 1997) and (b) recent evidence in stroke patients that AMPH boosts language acquisition (Walker-Batson et al, 2001).

Our study design allowed to disentangle effects generally related to noradrenergic drive, like cardiovascular and motor arousal, from learning-specific mechanisms underlying the observed enhanced language plasticity. Arousal effects were speeding of simple motor reaction times or increases in systolic blood pressure $(\sim 8 \mathrm{mmHg})$ and heart rate $(\sim 5$ beats $/ \mathrm{min})$ in the AMPHETAMINE group. These drug-induced arousal effects were, however, not correlated with the learning success during language training. The superior learning curves of the AMPHETAMINE group could not be explained with simple cardiovascular or motor arousal of AMPH. 

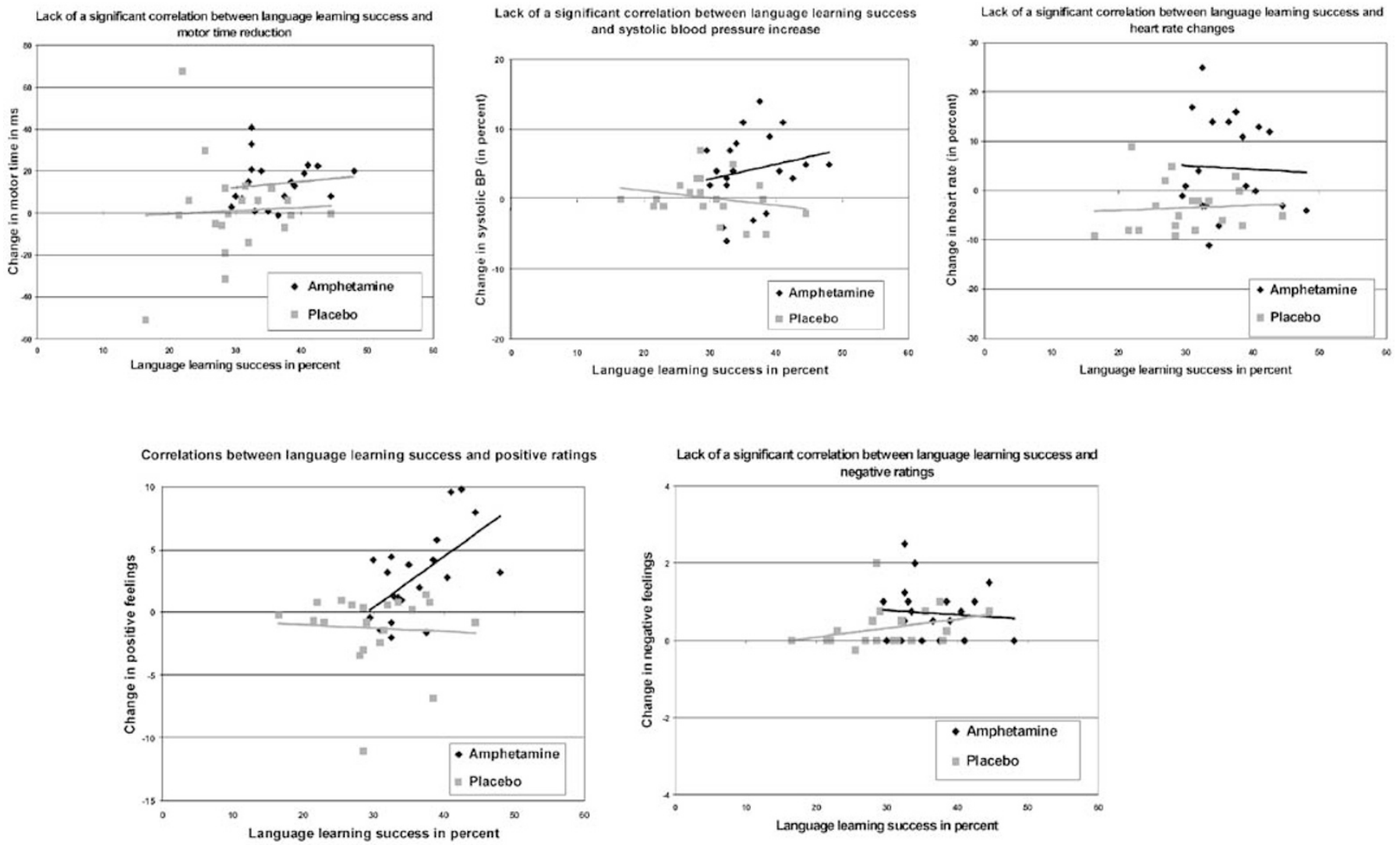

Figure 4 Correlations between language training success (X-axis: day 5 minus day I) and a reduction in simple motor time (top left corner), systolic blood pressure increases (top center), heart rate increases (top right), positive (bottom left) and negative (bottom right) mood ratings for the AMPHETAMINE and the PLACEBO groups. Note that the only significant correlation was between language learning success and positive ratings in the AMPHETAMINE group (lower left corner).

This is in contrast to the findings in animals in which post-lesional AMPH-facilitated motor recovery has been related to its noradrenergic arousing actions (Goldstein, 1997), based on a seminal series of animal experiments by Feeney (Boyeson and Feeney, 1990; Feeney et al, 1982; Hovda and Feeney, 1984). In these studies, the plasticityenhancing effect could selectively be attributed to the noradrenergic system (Goldstein, 2003; Sutton and Feeney, 1992). A crucial component for successful recovery was concomitant motor or visual experience in all studies. Positive effects of AMPH were even found when rats were merely allowed to move freely without a task-specific training schedule (Goldstein and Davis, 1990). It is possible that noradrenergic actions are crucial in animal recovery models because they induce spontaneous motor (eg hyperactivity) (Feeney and Hovda, 1985) and visual explorative behavior. Without the activity-stimulating effect of noradrenaline, the animals may simply not move voluntarily in their cages between test sessions, thus restricting afferent input required for new neural network formation. It seems as if the spontaneous motor activity in the home cage was more important in providing afferent input for the reorganization process than the supervised sessions. The 'training program' frequently required a single beam-walking run per assessment only (Feeney et al, 1982). Conversely, spontaneous motor activity is a less-important aspect in humans recovering from stroke symptoms, particularly with respect to language rehabilitation. Patients' cooperation is based on self-discipline, and the amount of afferent speech input is determined by the structure of the training program. With a high intensity of the training schedule, as in our language training approach, the amount of spontaneous (locomotor or language) activity between training sessions is less crucial for the overall outcome of functional recovery. In humans, as opposed to animals, general arousing effects of AMPH could therefore play a less-important role in functional recovery post stroke.

AMPH promotes the release of catecholamines from peripheral and central nerve terminals and, thus, serves as an indirect catecholaminergic agonist. The AMPH doses required to boost recovery affect mainly noradrenergic, dopaminergic, and, to a lesser extent, serotonergic neurotransmission (Hurwitz et al, 1991). The design of our study does not allow to directly disentangle noradrenergic from dopaminergic effects of AMPH. However, our study indicates that the learning-enhancing effect of AMPH may not be primarily noradrenergic. The single best predictor of language learning success in our study was an increase in positive feelings in the AMPHETAMINE group. A series of recent studies has shown that AMPH-induced positive feelings were correlated with the amount of dopamine release in healthy humans (Abi-Dargham et al, 2003; Cardenas et al, 2004; Drevets et al, 1999; Martinez et al, 
2003). This raises the possibility that other actions of AMPH underly the observed improvement of learning.

Antidepressants with noradrenergic effects are frequently used in poststroke rehabilitation. Their effect on cognitive recovery poststroke has not been studied systematically. Studies with healthy subjects generally suggest that noradrenergic actions mediate the influence of emotional arousal on memory consolidation (eg Southwick et al, 2002), presumably through its action on the amygdala (McIntyre et al, 2003). Data with healthy subjects, however, are not consistent, with some studies failing to observe enhanced memory consolidation for emotional material after selectively manipulating the noradrenergic system (Papps et al, 2002). Of particular interest with respect to the opposing effects on memory performance with different noradrenergic substances (yohimbine vs reboxetine) is the fact that both substances increased heart rate compared to placebo (cf Papps et al, 2002). This supports our conclusion that AMPH's effects on memory consolidation are independent of its arousal effects. Studies on depression and anxiety most consistently support the view of an overactivation of the noradrenergic systems (Ressler and Nemeroff, 2000), and the resulting cortical dysregulation-presumably involving other transmitter systems - may contribute to impaired attention and memory (Ressler and Nemeroff, 1999). Antidepressant treatment success is consequently attributed to a decrease of noradrenergic transmission in the hippocampus/amygdala system (Mongeau et al, 1997). In summary, administration of antidepressants with noradrenergic effects to stroke patients may only affect emotional learning, and not general memory consolidation.

The relevance to language reacquisition in stroke patients with aphasia is the most important aspect of our model, but it is undoubtedly also problematic. There is no universally accepted standard treatment program for stroke patients suffering from aphasia. Word finding difficulties are generally treated by presenting patients with real or picture objects, together with the correct object label in written or spoken form (or a variety of related visual and acoustic cues). A treatment goal is that the patient is able to generate the correct object label spontaneously. Our model was designed to structurally match this standard rehabilitation approach, based on the understanding that 'techniques most successful in normal subjects for solving a given task can be used as a starting point for implementing a therapeutic method for patients' (Basso et al, 2001, p 47). We added another important feature, which makes our model particularly suitable for training stroke patients with reduced attentional capabilities. Owing to its incidental (associative) learning principle, the model is suitable for high-frequency training programs in brain-damaged populations. Recent experimental (Basso and Caporali, 2001; Pulvermuller et al, 2001) and review work (Bhogal et al, 2003a; Bhogal et al, 2003b; Robey, 1994) on aphasia therapy has suggested that training intensity may in fact play the most important role in predicting treatment success in aphasia. Furthermore, in a still-ongoing study, we collected the first evidence that some patients with aphasia may benefit from our word-learning model. A single training session with a nonfluent patient with chronic aphasia, who presented with anomia but relatively unimpaired performance in other cognitive domains, yielded a training success, which was significantly better than expected by chance.

In summary, we do not recommend the administration of $\mathrm{AMPH}$ as a general clinical practice in stroke therapy because of its cardiovascular side effects. Our results do, however, provide the basis for future studies systematically examining learning-enhancing drugs without cardiovascular side effects in the treatment of stroke with aphasia. For example, selective dopaminergic agents need to be studied to clarify whether the dopamine neuromodulatory system is in fact the molecular basis of the enhanced learning effect. A significantly larger percentage of stroke patients might be eligible for treatment by avoiding AMPH and using lessadverse drugs to promote restoration of cerebral functions.

\section{ACKNOWLEDGEMENTS}

This research was supported by a grant from the Innovative Medizinische Forschung of the Medical Faculty of the University of Münster (BR 110226) and by a grant from the Wissenschaftsministerium Nordrhein-Westfalen (Nachwuchsgruppe Knecht 2000 NWG). The funding organizations had no involvement in the study design. We are grateful to Ingrid Neuhaus, pharmacist, and Julia Bernotat for their help with data acquisition. We gratefully acknowledge Dr Inta Jacobi's, Dr Agnes Flöel's, and Dr Stuart Brody's critical comments on an earlier manuscript version.

\section{REFERENCES}

Abi-Dargham A, Kegeles LS, Martinez D, Innis RB, Laruelle M (2003). Dopamine mediation of positive reinforcing effects of amphetamine in stimulant naive healthy volunteers: results from a large cohort. Eur Neuropsychopharmacol 13: 459-468.

Barch DM (2004). Pharmacological manipulation of human working memory. Psychopharmacology (Berl) (in press).

Basso A, Caporali A (2001). Aphasia therapy or the importance of being earnest. Aphasiology 15: 307-332.

Basso A, Marangolo P, Piras F, Galluzzi C (2001). Acquisition of new 'words' in normal subjects: a suggestion for the treatment of anomia. Brain Lang 77: 45-59.

Bhogal SK, Teasell R, Speechley M (2003a). Intensity of aphasia therapy, impact on recovery. Stroke 34: 987-993.

Bhogal SK, Teasell RW, Foley NC, Speechley MR (2003b). Rehabilitation of aphasia: more is better. Top Stroke Rehabil 10: 66-76.

Boyeson MG, Feeney DM (1990). Intraventricular norepinephrine facilitates motor recovery following sensorimotor cortex injury. Pharmacol Biochem Behav 35: 497-501.

Breitenstein C, Knecht S (2002). Development and validation of a language learning model for behavioral and functional-imaging studies. J Neurosci Methods 114: 173-179.

Breitenstein C, Knecht S (2003). Spracherwerb und statistisches Lernen (Language acquisition and statistical learning). Nervenarzt 74: 133-143.

Cardenas L, Houle S, Kapur S, Busto UE (2004). Oral D-amphetamine causes prolonged displacement of $\left[{ }^{11} \mathrm{C}\right]$ raclopride as measured by PET. Synapse 51: 27-31.

Crisostomo EA, Duncan PW, Propst M, Dawson DV, Davis JN (1988). Evidence that amphetamine with physical therapy promotes recovery of motor function in stroke patients. Ann Neurol 23: 94-97. 
Drevets WC, Price JC, Kupfer DJ, Kinahan PE, Lopresti B, Holt D et al (1999). PET measures of amphetamine-induced dopamine release in ventral versus dorsal striatum. Neuropsychopharmacology 21: 694-709.

Feeney DM, Gonzalez A, Law WA (1982). Amphetamine, haloperidol, and experience interact to affect rate of recovery after motor cortex injury. Science 217: 855-857.

Feeney DM, Hovda DA (1985). Reinstatement of binocular depth perception by amphetamine and visual experience after visual cortex ablation. Brain Res 342: 352-356.

Gladstone DJ, Black SE (2000). Enhancing recovery after stroke with noradrenergic pharmacotherapy: a new frontier? Can $J$ Neurol Sci 27: 97-105.

Goldstein LB (1997). Influence of common drugs and related factors on stroke outcome. Curr Opin Neurol 10: 52-57.

Goldstein LB (1999). Amphetamine-facilitated poststroke recovery (letter; comment). Stroke 30: 696-698.

Goldstein LB (2003). Amphetamines and related drugs in motor recovery after stroke. Phys Med Rehabil Clin N Am 14: S125-S134.

Goldstein LB, Davis JN (1990). Post-lesion practice and amphetamine-facilitated recovery of beam-walking in the rat. Restor Neurol Neurosci 1: 311-314.

Groves PM, Rebec GV (1976). Biochemistry and behavior: some central actions of amphetamine and antipsychotic drugs. Annu Rev Psychol 27: 91-127.

Hovda DA, Feeney DM (1984). Amphetamine with experience promotes recovery of locomotor function after unilateral frontal cortex injury in the cat. Brain Res 298: 358-361.

Hurwitz BE, Dietrich WD, Mc Cabe PM, Alonson BD, Watson BD (1991). Amphetamine promotes recovery from sensory-motro integration deficit after thrombotic infarction of the primary somatosensory rat cortex. Stroke 22: 648-654.

Knecht S, Breitenstein C, Bushuven S, Wailke S, Kamping S, Zwitserlood P et al (2004). Faster and better word learning with dopamine. Ann Neurol (in press).

Knecht S, Deppe M, Ringelstein EB (1999). Determination of cognitive hemispheric lateralization by 'Functional' transcranial Doppler cross-validated by functional MRI. Stroke 30: 2491-2492.

Krohne HW, Egloff B, Kohlmann CW, Tausch A (1996). Untersuchungen mit einer deutschen Version der 'Positive and Negative Affect Schedule' (PANAS) (Investigations with a German version of the Positive and Negative Affect Schedule (PANAS)). Diagnostica 42: 139-156.

Kulisevsky J (2000). Role of dopamine in learning and memory. Drugs Aging 16: 365-379.

Kumari V, Corr PJ, Mulligan OF, Cotter PA, Checkley SA, Gray JA (1997). Effects of acute administration of D-amphetamine and haloperidol on procedural learning in man. Psychopharmacology (Berl) 129: 271-276.

Martinez D, Slifstein M, Broft A, Mawlawi O, Hwang DR, Huang Y et al (2003). Imaging human mesolimbic dopamine transmission with positron emission tomography. Part II: Amphetamineinduced dopamine release in the functional subdivisions of the striatum. J Cereb Blood Flow Metab 23: 285-300.

Martinsson L, Eksborg S (2004). Drugs for stroke recovery: the example of amphetamines. Drugs Aging 21: 67-79.

Martinsson L, Wahlgren NG (2003). Safety of dexamphetamine in acute ischemic stroke: a randomized, double-blind, controlled dose-escalation trial. Stroke 34: 475-481.

Martinsson L, Wahlgren NG, Hardemark HG (2003). Amphetamines for improving recovery after stroke. Cochrane Database Syst Rev, CD002090.

Mattay VS, Berman KF, Ostrem JL, Esposito G, Van Horn JD, Bigelow LB et al (1996). Dextroamphetamine enhances 'neural network-specific' physiological signals: a positron-emission tomography rCBF study. J Neurosci 16: 4816-4822.
Mattay VS, Callicott JH, Bertolino A, Heaton I, Frank JA, Coppola $\mathrm{R}$ et al (2000). Effects of dextroamphetamine on cognitive performance and cortical activation. Neuroimage 12: 268-275.

Mattay VS, Goldberg TE, Fera F, Hariri AR, Tessitore A, Egan MF et al (2003). Catechol O-methyltransferase val158-met genotype and individual variation in the brain response to amphetamine. Proc Natl Acad Sci USA 100: 6186-6191.

McIntyre CK, Power AE, Roozendaal B, McGaugh JL (2003). Role of the basolateral amygdala in memory consolidation. Ann NY Acad Sci 985: 273-293.

Mongeau R, Blier P, de Montigny C (1997). The serotonergic and noradrenergic systems of the hippocampus: their interactions and the effects of antidepressant treatments. Brain Res Brain Res Rev 23: 145-195.

Nutt JG, Fellman JH (1984). Pharmacokinetics of levodopa. Clin Neuropharmacol 7: 35-49.

Oldfield RC (1971). The assessment and analysis of handedness: the Edinburgh inventory. Neuropsychologia 9: 97-113.

Papps BP, Shajahan PM, Ebmeier KP, O'Carroll RE (2002). The effects of noradrenergic re-uptake inhibition on memory encoding in man. Psychopharmacology (Berl) 159: 311-318.

Pulvermuller F, Neininger B, Elbert T, Mohr B, Rockstroh B, Koebbel $\mathrm{P}$ et al (2001). Constraint-induced therapy of chronic aphasia after stroke. Stroke 32: 1621-1626.

Ressler KJ, Nemeroff CB (1999). Role of norepinephrine in the pathophysiology and treatment of mood disorders. Biol Psychiatry 46: 1219-1233.

Ressler KJ, Nemeroff CB (2000). Role of serotonergic and noradrenergic systems in the pathophysiology of depression and anxiety disorders. Depress Anxiety 12 Suppl 1: 2-19.

Robey RR (1994). The efficacy of treatment for aphasic persons: a meta-analysis. Brain Lang 47: 582-608.

Scheidtmann K, Fries W, Muller F, Koenig E (2001). Effect of levodopa in combination with physiotherapy on functional motor recovery after stroke: a prospective, randomised, doubleblind study. Lancet 358: 787-790.

Servan-Schreiber D, Carter CS, Bruno RM, Cohen JD (1998). Dopamine and the mechanisms of cognition: Part II. D-Amphetamine effects in human subjects performing a selective attention task. Biol Psychiatry 43: 723-729.

Soetens E, Casaer S, D'Hooge R, Hueting JE (1995). Effect of amphetamine on long-term retention of verbal material. Psychopharmacology (Berl) 119: 155-162.

Soetens E, D'Hooge R, Hueting JE (1993). Amphetamine enhances human-memory consolidation. Neurosci Lett 161: 9-12.

Sonde L, Nordstrom M, Nilsson CG, Lokk J, Viitanen M (2001). A double-blind placebo-controlled study of the effects of amphetamine and physiotherapy after stroke. Cerebrovasc Dis 12: 253-257.

Southwick SM, Davis M, Horner B, Cahill L, Morgan CA, III Gold PE et al (2002). Relationship of enhanced norepinephrine activity during memory consolidation to enhanced long-term memory in humans. Am J Psychiatry 159: $1420-1422$.

Sutton RL, Feeney DM (1992). Alpha-noradrenergic agonists and antagonists affect recovery and maintenance of beam-walking ability after sensorimotor cortex ablation in the rat. Restor Neurol Neurosci 4: 1-11.

Treig T, Werner C, Sachse M, Hesse S (2003). No benefit from D-amphetamine when added to physiotherapy after stroke: a randomized, placebo-controlled study. Clin Rehabil 17: 590-599.

Walker-Batson D (2000). Use of pharmacotherapy in the treatment of aphasia. Brain Lang 71: 252-254.

Walker-Batson D, Curtis S, Natarajan R, Ford J, Dronkers N, Salmeron E et al (2001). A double-blind, placebo-controlled 
study of the use of amphetamine in the treatment of aphasia. Stroke 32: 2093-2098.

Walker-Batson D, Smith P, Curtis S, Unwin H, Greenlee R (1995). Amphetamine paired with physical therapy accelerates motor recovery after stroke. Further evidence Stroke 26: 2254-2259.
Walker-Batson D, Unwin H, Curtis S, Allen E, Wood M, Smith P et al (1992). Use of amphetamine in the treatment of aphasia. Restor Neurol Neurosci 4: 47-50.

Watson D, Clark LA, Tellegen A (1988). Development and validation of brief measures of positive and negative affect: the PANAS scales. J Pers Soc Psychol 54: 1063-1070. 